\title{
A probable case of Legg-Calvé-Perthes disease in Warring States-era China
}

\author{
Elizabeth Berger, University of North Carolina at Chapel Hill, Department of Anthropology, \\ Research Laboratories of Archaeology ${ }^{\text {* }}$ * \\ Liang Chen, Northwest University School of Cultural Heritage ${ }^{\mathrm{b}}$ \\ Zhouyong Sun, Shaanxi Provincial Archaeological Research Institute ${ }^{c}$ \\ Zhanwei Sun, Shaanxi Provincial Archaeological Research Institute ${ }^{c}$
}

\begin{abstract}
Reports of Legg-Calvé-Perthes disease (LCPD) in the paleopathological literature are rare. Here, the authors present a probable case of LCPD, which presents as abnormal morphology of the proximal femur. The condition was observed in an individual of the Warring States period in Shaanxi Province, China, and the morphology involves a "mushroom head" deformity of the proximal right femur and an enlarged acetabulum, along with a contralateral tibia, talus, and navicular that are enlarged and demonstrate periosteal new bone formation. The authors consider tuberculosis, septic arthritis, trauma, slipped capital femoral epiphysis, and Legg-Calvé-Perthes disease in a differential diagnosis. The authors conclude that the most likely diagnosis for the deformity is Legg-Calvé-Perthes disease. Bony changes in the hip joint and contralateral lower leg suggest that the individual had an altered gait because of the condition.
\end{abstract}

\section{Keywords}

China, paleopathology, Legg-Calvé-Perthes disease, femoral head necrosis

\footnotetext{
${ }^{a}$ University of North Carolina at Chapel Hill Department of Anthropology, 301 Alumni Building, CB\#3115, UNC$\mathrm{CH}$, Chapel Hill, NC 27599 USA

b Northwest University School of Cultural Heritage, 229 Taibai North Road, Xi'an, China

' Shaanxi Provincial Archaeological Research Institute, 31 Leyou Road, Yanta District, Xi'an, China

*Corresponding author at: UNC-CH 301 Alumni Building, CB\#3115, UNC-CH, Chapel Hill, NC 27599 USA Email: eberger@live.unc.edu (E.S. Berger)
} 


\section{Introduction}

Osteonecrosis of the femoral head is rarely observed in the archaeological record (Smrcka et al., 2009). The condition can cause severe deformity of the hip joint in the absence of modern surgical intervention, and can involve sequelae such as infection and osteoarthritis. The case presented here involves osteonecrosis and deformity in the hip of a young adult male individual. The individual also exhibits an altered acetabulum and extensive bony changes in the lower legs, indicating that the hip deformity affected the individual's gait. The authors present a differential diagnosis of this condition and discuss its significance.

\section{Case description}

Individual SHSM22 is a male (Buikstra and Ubelaker, 1994; Klales et al., 2012; Liu, 1989) aged 20-29 at death (Brooks and Suchey, 1990; Buikstra and Ubelaker, 1994; Iscan, 1991; Langley-Shirley and Jantz, 2010; Lovejoy et al., 1985), interred during the Warring States period (475-221 BCE) in the Shijiahe cemetery, in what is now northern Shaanxi Province, China. The cemetery was used, possibly simultaneously, by two groups: low status subjects of the State of Qin $(\mathrm{N}=10)$, who were likely moved into the area after its conquest by Qin; and a group known in historical sources as the "Rong" ( $=24)$, who textual, archaeological, and bioarchaeological sources agree migrated from semi-arid Western China, allied themselves with Chinese states, and settled within the states' borders (Shaanxi, 2013; Sun et al., 2015). The Rong remains show a small but measurable biological distance from the Qin, though skeletal measures of their community health are nearly identical and suggest they had similar lifeways (Berger, dissertation in progress). The Qin graves have side burial chambers and are positioned around the margins of the cemetery. SHSM22 came from one of the Rong graves, in the densest area of the cemetery. 
The remains were examined macroscopically at the Northwest University School of Cultural Heritage in Xi'an; radiographs were not obtainable. The right femoral head of this individual is deformed, exhibiting a "mushroom" shape. The head is flattened (Figure 1), and the fovea capitis is located at the medial inferior margin of the head. The greater trochanter is also enlarged and shows extensive periosteal new bone formation. The corresponding acetabulum is enlarged, especially on the lateral margin, with a loss of sphericity (Figure 2). No evidence of infection of the bone, or callus formation indicative of a fracture, are visible.

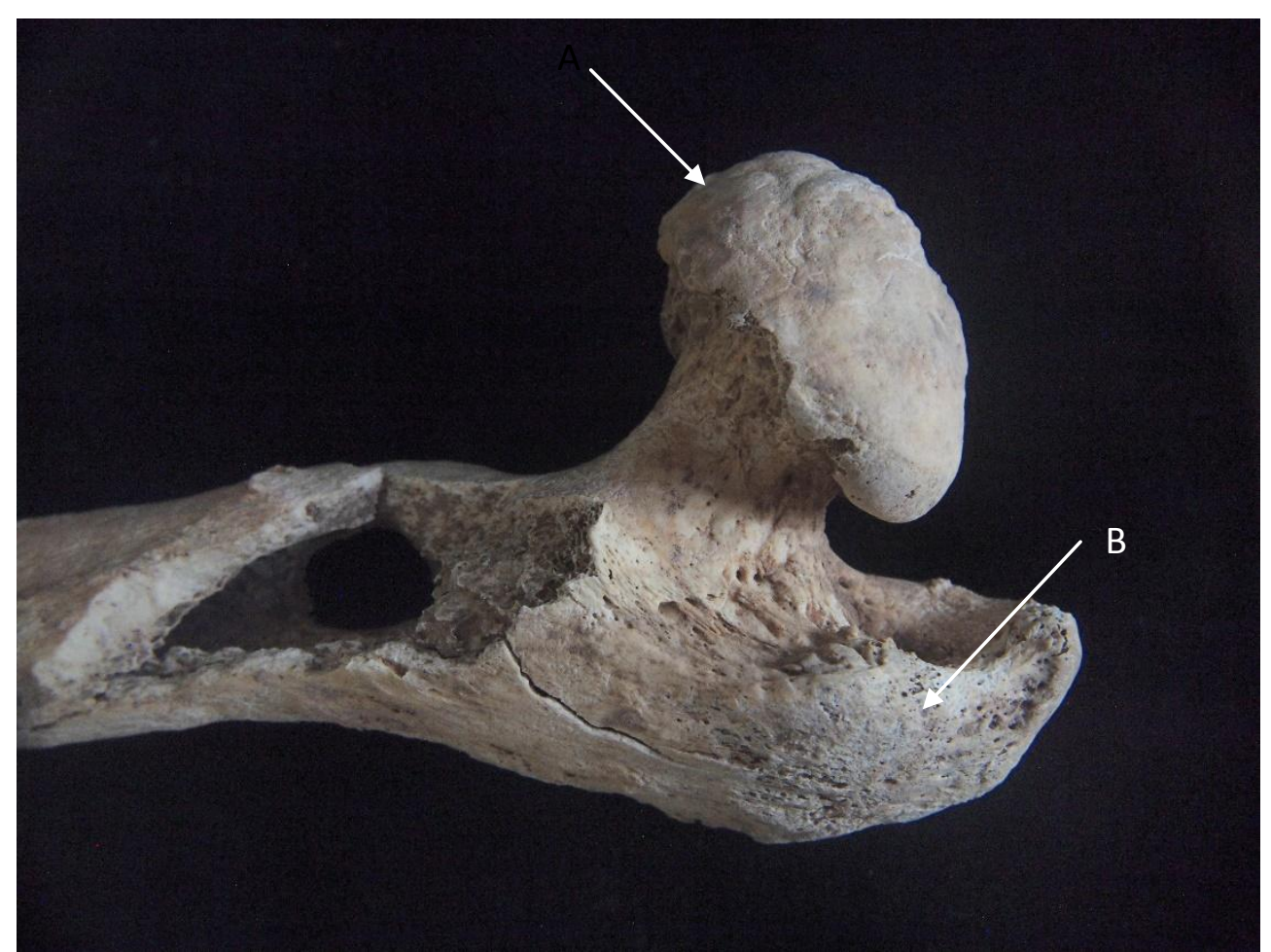

Figure 1 Posterior view of SHSM22 proximal right femur with "mushroom" deformity (A) and periosteal new bone on the greater trochanter (B). The opening below the femoral neck is postmortem damage. 


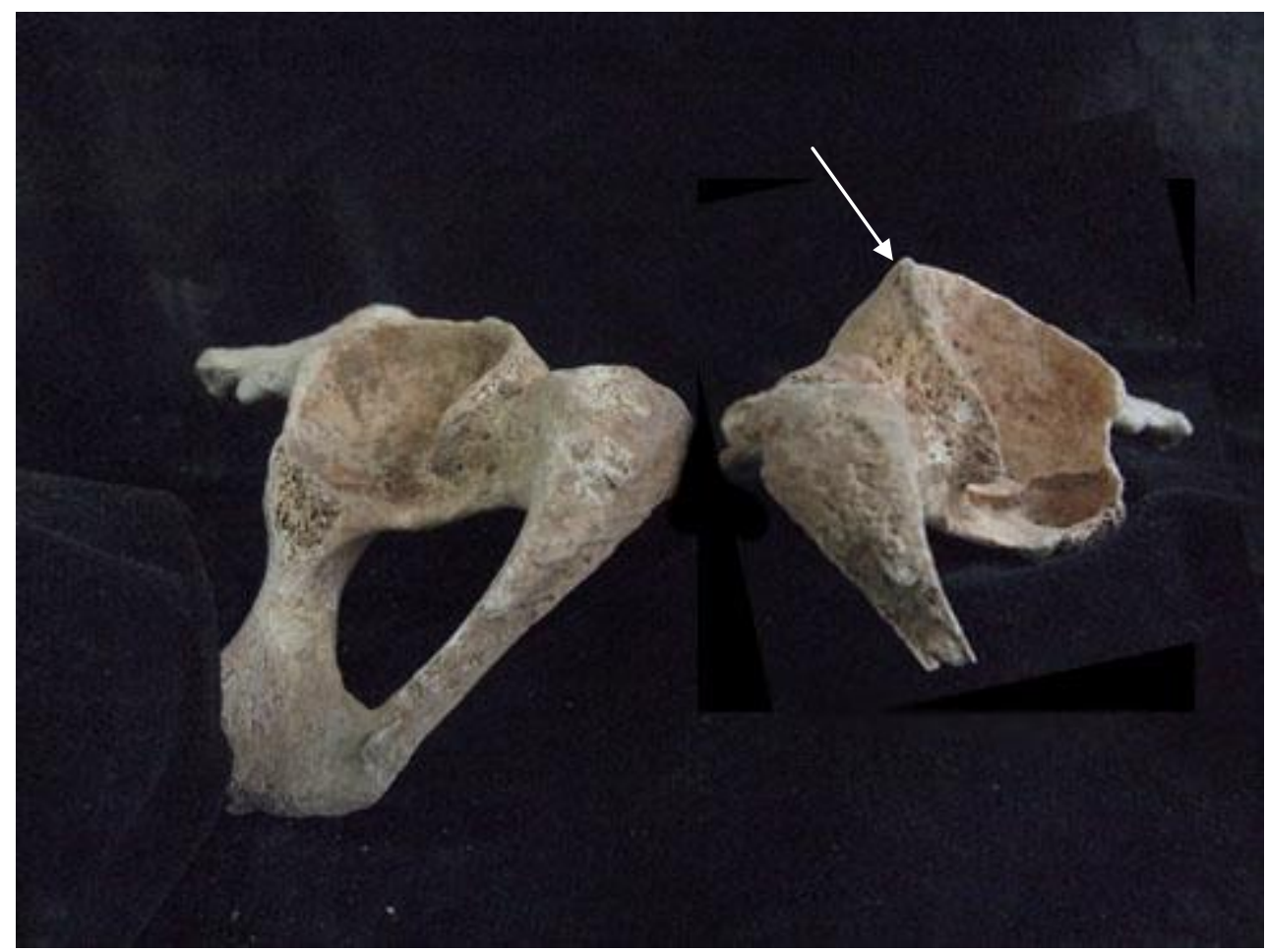

Figure 2 Antero-inferior view of ossa coxae of SHSM22, showing enlarged lateral margin of the right acetabulum (arrow).

The tibial shafts exhibit some striated appositional bone, both woven and remodeled, resembling healing periosteal new bone. The left (contralateral) tibia is larger than the right in both length and diameter (right tibia maximum length $351 \mathrm{~mm}$, maximum distal epiphyseal breadth $46.21 \mathrm{~mm}$; left tibia maximum length $372 \mathrm{~mm}$, maximum distal epiphyseal breadth $54.51 \mathrm{~mm}$ ), and the distal left tibia has appositional bone on the surface (Figure 3). The left talus and navicular bone are also enlarged, with undulating solid surfaces, and lipping, faint porosity, and osteophytes (Figure 4). These changes are especially seen on the talonavicular joint surfaces and the superior articular surface of the talus. Finally, vertebra L5 shows a complete spondylolysis fracture with no reattachment. 


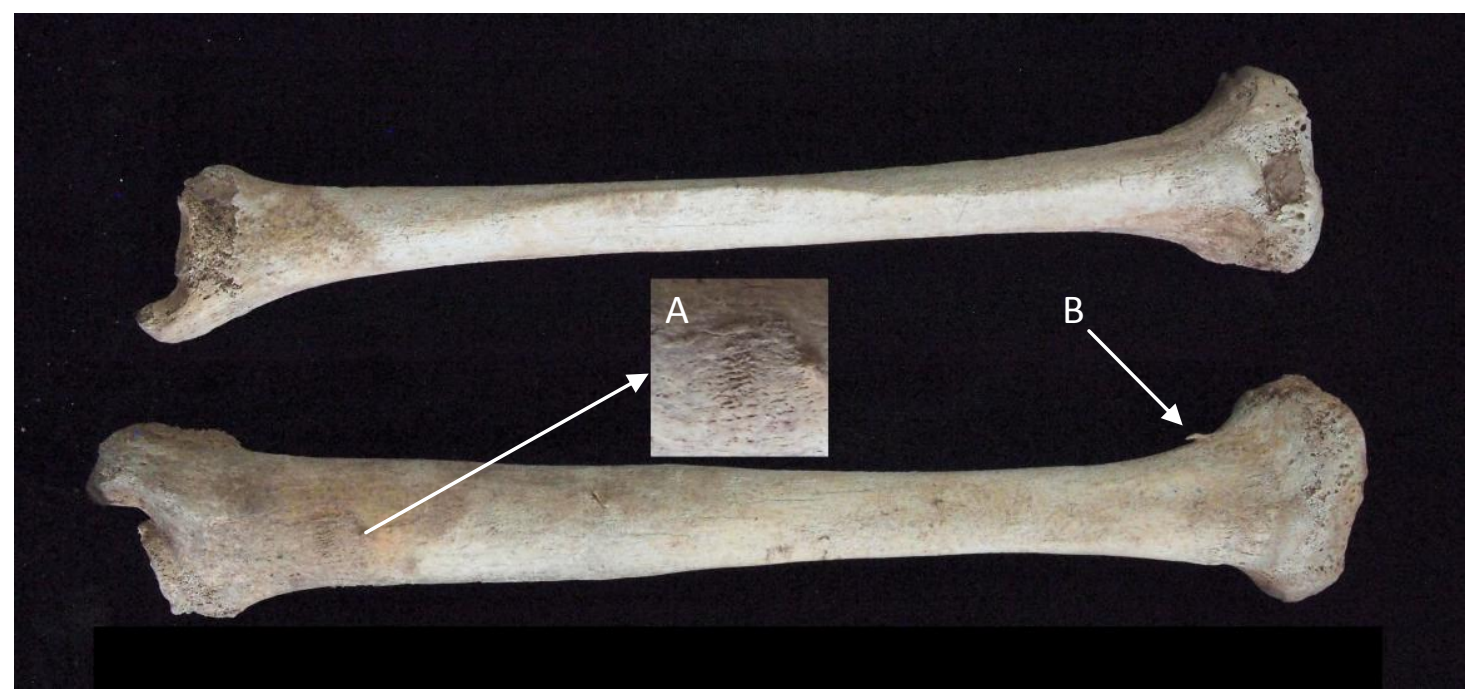

Figure 3 Anterior view of tibiae of SHSM22. Note enlarged size, periosteal new bone (A, inset), and enthesophyte on medial proximal shaft $(B)$ of the left tibia.

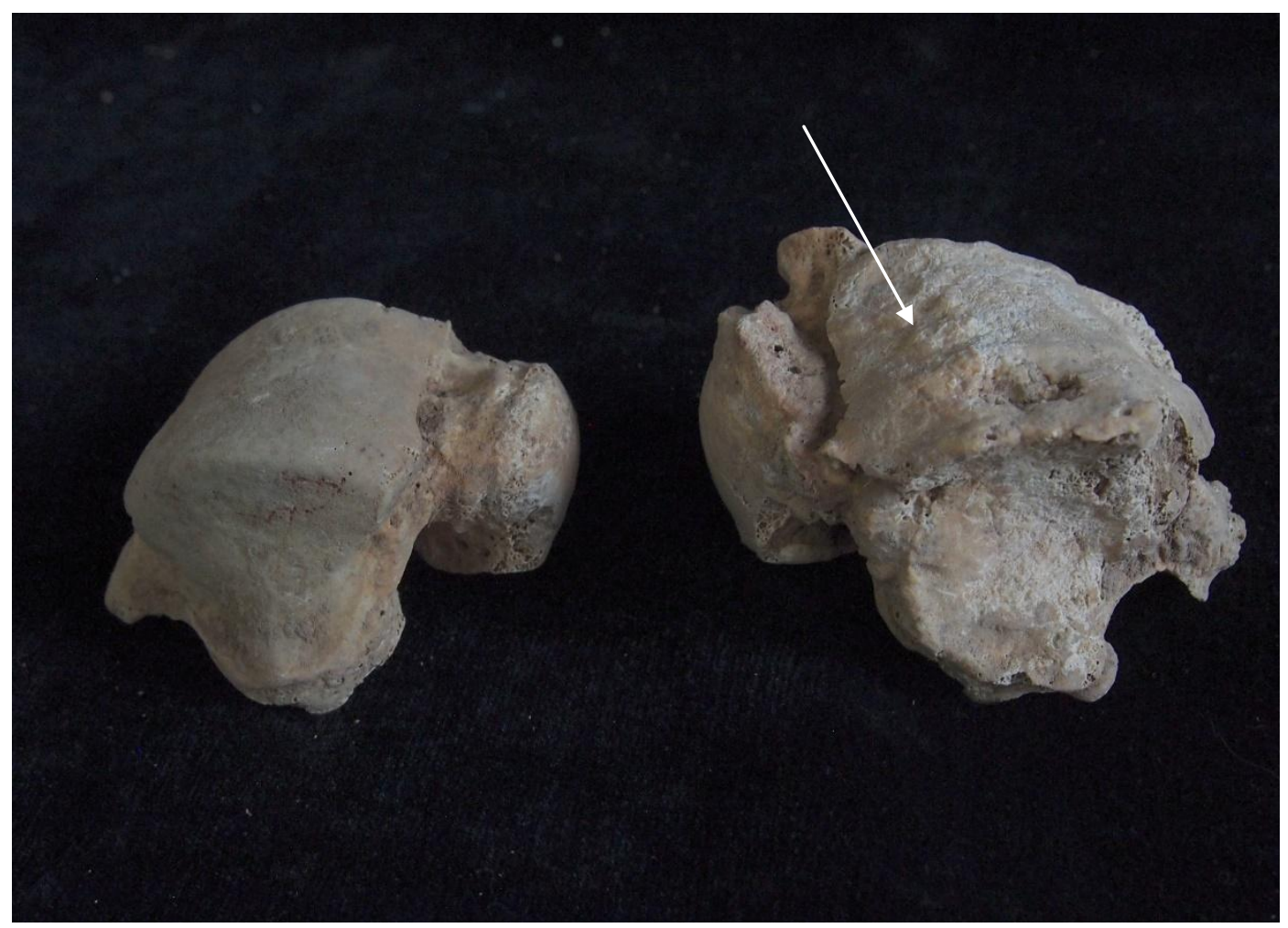

Figure 4 Medial view of tali of SHSM22. Note enlarged size of the left talus and rugosity of the superior articular surface (arrow).

A differential diagnosis suggests that this is likely a case of Legg-Calvé-Perthes disease (Table 1). The presentation also closely resembles that of slipped capital femoral epiphysis (SCFE), except that in SCFE the femoral neck is severely shortened (Ortner, 2003, p. 349), 
which is not the case for SHSM22. In the case of SHSM22, the normal femoral neck length,

flattened femoral head, unilateral presentation, and lack of evidence for infection are consistent

with a diagnosis of Legg-Calvé-Perthes disease.

Table 1: Conditions considered in the differential diagnosis of SHSM22

\begin{tabular}{|c|c|}
\hline Pathological condition & Diagnostic characteristics \\
\hline Tuberculosis $^{\text {ab }}$ & $\begin{array}{l}\text { Involvement of the hip is the second most common skeletal } \\
\text { symptom after spondylitis. The disease can cause destruction } \\
\text { of the femoral neck and head and the acetabulum. SHSM } 22 \\
\text { lacks the appearance of infection, as well as vertebral } \\
\text { involvement. }\end{array}$ \\
\hline Septic arthritis ${ }^{\text {ac }}$ & $\begin{array}{l}\text { Bacteria are introduced into the synovium of the joint. Hip } \\
\text { involvement is common, and chronic sepsis results in some } \\
\text { degree of destruction of the femoral head and neck, sometimes } \\
\text { in addition to osteomyelitis and ankylosis of the hip joint. } \\
\text { SHSM22 does not display destruction of the cortical bone of } \\
\text { the femoral head and neck, only an altered shape of the } \\
\text { femoral head that indicates collapse of the trabecular bone, and } \\
\text { no indication of infection other than periosteal bone } \\
\text { deposition. }\end{array}$ \\
\hline $\begin{array}{l}\text { Trauma (including subchondral } \\
\text { bone injuries) }\end{array}$ & $\begin{array}{l}\text { Fracture of the femoral neck commonly leads to interruption of } \\
\text { blood supply and avascular necrosis of the femoral head. The } \\
\text { necrotic bone often includes visible dead trabecular bone, and } \\
\text { the antero-lateral part of the femoral head will be most affected } \\
\text { by structural collapse. Remodeling of the bone results in } \\
\text { thickened trabeculae with a sclerotic rim. Advanced age is the } \\
\text { greatest risk factor. In individual SHSM22, there is no visible } \\
\text { evidence of a fracture in the femoral neck, or the trochanteric } \\
\text { or subtrochenteric regions (though this cannot be assessed } \\
\text { thoroughly without radiographs). The head of the femur is not } \\
\text { significantly displaced, and the mushroom shape is not typical } \\
\text { of trauma in adulthood. } \\
\text { Fragmentation of articular cartilage can occur, sometimes with } \\
\text { fracture of subchondral bone. In these cases, a sequestrum } \\
\text { typically forms, and } 90 \% \text { of cases occur in the knee. There is } \\
\text { no visible evidence of a fracture or healing callous in the } \\
\text { subchondral portions of the femoral head of SHSM } 22 \text {, and the } \\
\text { pervasive deformity of the femoral head suggests a chronic } \\
\text { interruption of vascular supply, as in LCPD (though trauma } \\
\text { may play a role in some cases of LCPD). }\end{array}$ \\
\hline $\begin{array}{l}\text { Slipped capital femoral } \\
\text { epiphysis }(\mathrm{SCFE})^{\mathrm{ae}}\end{array}$ & $\begin{array}{l}\text { The unfused epiphysis is displaced, leading to displacement of } \\
\text { the femoral head and potentially to aseptic necrosis. The } \\
\text { epiphysis is typically displaced medially, posteriorly, and } \\
\text { inferiorly. The condition resembles Legg-Calvé-Perthes } \\
\text { disease (LCPD) in some ways, especially in its advanced } \\
\text { stages, after osteoarthritis has developed. However, in LCFE, }\end{array}$ \\
\hline
\end{tabular}




\begin{tabular}{|l|l|}
\hline & $\begin{array}{l}\text { the femoral neck is shortened, which is not observed in } \\
\text { SHSM22. }\end{array}$ \\
\hline $\begin{array}{l}\text { Legg-Calvé-Perthes disease } \\
\text { (LCPD)/coxa plana }{ }^{\text {Ta }}\end{array}$ & $\begin{array}{l}\text { The blood supply to the femoral head is interrupted for a } \\
\text { period of several years during growth, which is followed by } \\
\text { revascularization and often permanent deformity of the } \\
\text { femoral head. Most cases are unilateral. The "mushroom head" } \\
\text { results from the lack of endochondral growth and infarction of } \\
\text { the epiphysis. }\end{array}$ \\
\hline
\end{tabular}

${ }^{\mathrm{a}}$ Ortner (2003)

${ }^{\mathrm{b}}$ Vanhoenacker et al. (2009)

${ }^{\mathrm{c}}$ Choi et al. (1990)

${ }^{\mathrm{d}}$ Aiello (2015); Khurana (2009); Ortner (2003); Taylor (2006)

${ }^{\mathrm{e}}$ Gopinathan et al. (2012)

${ }^{f}$ Fornari et al. (2015); Khurana (2009); Wainwright and Catterall (2010); White et al. (2011).

\section{Discussion}

Legg-Calvé-Perthes disease (LCPD) is a developmental abnormality involving interruption of the blood supply to the femoral head for several years during growth, followed by revascularization and often permanent deformity of the femoral head. The disease's etiology is not well-understood; it may be initiated by traumatic injury, and in some cases, may be related to a systemic disorder involving a predisposition to vascular insult (Fornari et al., 2015; Khurana, 2009; Wainwright and Catterall, 2010; White et al., 2011). LCPD occurs in fewer than 20 in 100,000 people, usually presents in childhood, and occurs up to four times more often in males than in females (Fornari et al., 2015).

Femoroacetabular impingement (FAI) is a possible sequela of LCPD (Wainwright and Catterall, 2010), sometimes resulting in an enlarged acetabulum (Emary, 2010). In particular, LCPD often involves a widened acetabulum, from a combination of mechanical forces and hypertrophy of the triradiate cartilage (Huhnstock et al., 2014). However, FAI may also result from SCFE, so it does not help distinguish between LCPD and LCFE in the differential diagnosis. Enlargement of the acetabulum could also be the result of mechanical forces applied to the 
acetabular margin during lateral subluxation of the femoral head, which is possible in more advanced cases of LCPD (Rab, 2005) and indicates a poor prognosis (Kotoura et al., 2015).

SHSM22's left tibia, talus, and navicular bone, contralateral to the affected hip, appear enlarged and rugose, with some remodeling periosteal new bone. The talus and navicular bone are affected by possible osteoarthritis secondary to LCPD and mechanical stress due to an antalgic gait. Osteomyelitis cannot be ruled out as a cause for the bony changes in the lower leg, but is also not evident, as there are no cloacae visible. Herrerín and Garralda (2012) report a case of LCPD with an atrophied ipsilateral tibia; the smaller diameter and shorter length of the ipsilateral tibia in the case of SHSM22 could have a similar origin. There is also a small but pronounced enthesophyte on the medial side of the proximal shaft of the left tibia. This is the location of the pes anserinus, a complex of tendons of three leg muscles, which primarily functions in flexion of the knee (Noyes and Sonstegard, 1973). An enthesophyte here, on only one side, indicates an uneven gait, which is common in LCPD (ك̌vehlík et al., 2012; Westhoff et al., 2006; Westhoff et al., 2012).

Spondylolysis, such as that seen in the L5 vertebra, typically occurs as the result of a fatigue fracture from low-grade stress on the lower back (Ortner, 2003). This is not uncommon in adolescents, and generally results from a combination of congenital weakness in the pars interarticularis and strenuous physical activities, such as athletics or lifting heavy objects (Leone et al., 2011). This illustrates that though individual SHSM22 had an altered gait and somewhat impaired mobility, as well as chronic inflammation in the lower leg, he likely continued to participate in his community's labor activities. The dental health of this population is consistent with a diet high in starchy agricultural products (Berger, dissertation in progress), so it is possible that SHSM22 sustained the lumbar spine fracture while engaging in agricultural labor. 


\section{Conclusion}

The effect of trauma on SHSM22's condition cannot be further assessed without radiographs, but there is no visible evidence of a fracture. Epidemiological studies have shown that incidence of LCPD in certain populations is correlated with "deprivation," but this concept is poorly defined and not linked to specific causes other than a speculative link to poor diet (Kealey et al., 2000; Margets et al., 2001). This is a possibility at Shijiahe: Berger (dissertation in progress) has found a rise in linear enamel hypoplasias (LEH) in this population over previous periods (22.6\% of individuals), which may indicate growth interruptions in childhood linked to malnutrition. However, individual SHSM22 did not have LEH.

In modern populations, symptoms of mild cases of LCPD may resolve without intervention, but more severe cases can result in permanent altered gait and deformity (Wainwright and Catterall, 2010). It therefore appears that this individual suffered from a relatively severe case of LCPD. This is a significant finding, as reports of LCPD in the paleopathological literature are still rare, and the dry bone presentation is not often reported. The possible lateral subluxation of the femoral head is indicative of a more severe case of LCPD, and the enthesophyte and bony changes to the contralateral lower leg and foot indicate an altered gait. This individual therefore likely had impaired mobility. However, the spondylolysis of L5 indicates that despite his impairment, individual SHSM22 continued to engage in physical activities that put stress on the lumbar spine. Therefore, although the etiology of the condition in SHSM22 is difficult to assess, the case presents a picture of the progress of the untreated condition in an ancient individual, who still remained mobile and engaged in labor, despite his hip deformity. 


\section{Acknowledgments}

The authors would like to thank Dale Hutchinson, Sara Juengst, Sophia Dent, and Stephanie

Berger for thoughtful comments on earlier drafts of this paper. They also wish to thank the

Shaanxi Provincial Archaeological Research Institute and Northwest University in Xi'an, and the

University of North Carolina Research Laboratories of Archaeology. Financial support for the

work was provided by the National Geographic Society (Grant Number 9310-13) and the

National Science Foundation (Graduate Research Fellowship Fellow ID 2011120027). Our

gratitude also goes to the anonymous journal reviewers whose feedback improved this

manuscript.

\section{References}

Aiello M. 2015. Imaging in avascular necrosis of the femoral head. In: Chew F, editor: Medscape.

Berger E. In progress. Bioarchaeology of adaptation to climate change in ancient Northwest China. Chapel Hill, NC: The University of North Carolina at Chapel Hill.

Brooks S, and Suchey JM. 1990. Skeletal age determination based on the os pubis: A comparison of the Acsádi-Nemeskéri and Suchey-Brooks methods. Human Evolution 5(3):227-238.

Buikstra J, and Ubelaker D. 1994. Standards for Data Collection from Human Skeletal Remains. Fayetteville, AK: Arkansas Archaeological Survey.

Choi IH, Pizzutillo PD, Bowen JR, Dragann R, and Malhis T. 1990. Sequelae and reconstruction after septic arthritis of the hip in infants. The Journal of Bone \&amp;amp; Joint Surgery 72(8):1150.

Emary P. 2010. Femoroacetabular impingement syndrome: a narrative review for the chiropractor. Journal of the Canadian Chiropractice Association 54(3):164-176.

Fornari E, Karkenny A, and Shulz J. 2015. Legg-Calvé-Perthes Disease. Current Orthopaedic Practice 26(5):487-493.

Gopinathan N, Chouhan D, and Behera P. 2012. Case Report: Bilateral femoral neck fractures in a child and a rare complication of slipped capital epiphysis after internal fixation. Clinical Orthopaedics and Related Research 470:2941-2945.

Herrerín J, and Garralda MD. 2012. Legg-Calvé-Perthes disease and unifocal eosinophilic granuloma in a visigoth from the Duratón necropolis (Segovia, Spain). International Journal of Osteoarchaeology 22(1):86-97.

Huhnstock S, Svenningsen S, Pripp AH, Terjesen T, and Wiig O. 2014. The acetabulum in Perthes' disease: a prospective study of 123 children. Journal of Children's Orthopaedics 8(6):457-465.

Iscan MY. 1991. The aging process in the rib: An analysis of sex- and race-related morphological variation. American Journal of Human Biology 3:617-623. 
Kealey W, Moore A, Cook S, and Cosgrove A. 2000. Deprivation, urbanisation and Perthes' disease in Northern Ireland. The Journal of Bone and Joint Surgery (Br) 82(B):167-171.

Khurana J, editor. 2009. Bone Pathology. 2 ed. Philadelphia, PA: Humana.

Klales AR, Ousley SD, and Vollner JM. 2012. A revised method of sexing the human innominate using Phenice's nonmetric traits and statistical methods. American Journal of Physical Anthropology 149(1):104-114.

Kotoura Y, Kim WC, Hosokawa M, Yoshida T, Oka Y, Yamada N, Nakase M, Nishida A, Yokozeki K, Kusakabe T et al. . 2015. Assessment of lateral subluxation in Legg-CalvePerthes disease: a time-sequential study of magnetic resonance imaging and plain radiography. Journal of pediatric orthopedics Part B 24(6):493-506.

Langley-Shirley N, and Jantz RL. 2010. A Bayesian approach to age estimation in modern Americans from the clavicle. Journal of forensic sciences 55(3):571-583.

Leone A, Cianfoni A, Cerase A, Magarelli N, and Bonomo L. 2011. Lumbar spondylolysis: a review. Skeletal Radiology 40(6):683-700.

Liu W. 1989. Sex determination of Chinese femur by discriminant function. Journal of forensic sciences 34(5):1222-1227.

Lovejoy C, Meindl R, Pryzbeck TR, and Mensforth RP. 1985. Chronological metamorphosis of the auricular surface of the ilium. American Journal of Physical Anthropology 68:15-28.

Margets B, Perry C, Taylor J, and Dangerfield P. 2001. The incidence and distribution of LeggCalvé-Perthes' disease in Liverpool, 1982-95. Archives of Disease in Childhood 84:351354.

Noyes FR, and Sonstegard DA. 1973. Biomechanical function of the pes anserinus at the knee and the effect of its transplantation. The Journal of Bone and Joint Surgery (Am) 55(6):1225-1241.

Ortner DJ. 2003. Identification of Pathological Conditions in Human Skeletal Remains. Boston: Academic Press.

Rab GT. 2005. Theoretical study of subluxation in early Legg-Calve-Perthes disease. Journal of pediatric orthopedics 25(6):728-733.

Shaanxi sheng kaogu yanjiuyuan. 2013. 2012 nian Shaanxi sheng kaogu yanjiuyuan kaogu fajue xin shouhuo [New discoveries in excavations of the Shaanxi Provincial Institute of Archaeology in 2012]. Kaogu yu wenwu 2:3-10.

Smrcka V, Marik I, Svenssonova M, and Likovsky J. 2009. Case reports: Legg-Calve-Perthes disease in Czech archaeological material. Clin Orthop Relat Res 467(1):293-297.

Sun Z, Sun Z, and Shao J. 2015. Huangling Shijiahe Zhanguo mudi xiangguan wenti tantao [On the related issues of the Shijiahe Warring States cemetery in Huangling]. Kaogu yu wenwu 2015(3):60-66.

Švehlík M, Kraus T, Steinwender G, Zwick EB, and Linhart WE. 2012. Pathological gait in children with Legg-Calvé-Perthes disease and proposal for gait modification to decrease the hip joint loading. International Orthopaedics 36(6):1235-1241.

Taylor R, editor. 2006. Musculoskeletal Problems and Injuries, a Handbook. New York, NY: Springer.

Vanhoenacker F, Sanghvi D, and De Backer A. 2009. Imaging features of extraaxial musculoskeletal tuberculosis. Indian Journal of Radiology and Imaging 19(3):176-186.

Wainwright AM, and Catterall A. 2010. Legg-Calvé-Perthes disease. In: Benson M, Fixsen J, Macnicol M, and Parsch K, editors. Children's Orthopaedics and Fractures. London: Springer. p 465-480. 
Westhoff B, Petermann A, Hirsch MA, Willers R, and Krauspe R. 2006. Computerized gait analysis in Legg Calve Perthes disease--analysis of the frontal plane. Gait Posture 24(2):196-202.

Westhoff BS, Zilkens C, Müller-Reinartz A, Rosenthal D, and Krauspe R. 2012. Gait deviations in patients with longterm follow-up after Legg-Calvé-Perthes disease. Gait \& Posture 36:S47-S48.

White T, Black M, and Folkens P. 2011. Human Osteology. Boston: Elsevier/AP. 